\title{
ENERGY SAVING IN STAR MARKED REFRIGERATORS AND EFFECT OF DOOR OPENING FREQUENCY ON ENERGY CONSUMPTION OF RESIDENTIAL REFRIGERATORS
}

\author{
Bhabaranjan Sarmah ${ }^{1}$ \\ ${ }^{1}$ Assam Engineering Institute, Guwahati, Assam, India
}

\begin{abstract}
The resurgent economy of India is in need of energy as it is one of the vital requirements for a sustainable development. So, it is obvious that India will need a huge hike in energy to fulfill its requirements in the next decades. But, there is a large gap between the demand and supply. All India average energy shortfall is 9\% and peak demand shortfall is 14\% [O'Neill 2009]. .Loss of electricity in India, due to transmission, is around 24\% during 2011-12 [Energy statistics 2013]. Energy saved at the point of use is equivalent to 2.5 times the energy produced [Deshpande V.M.,2011]. As such sincere effort is essential in every aspect wherever there is a possibility of saving energy. Refrigerators are huge consumer of electrical energy. In India, $13 \%$ of residential electricity is used by refrigeration systems [BEE, Energy and Building, 2014 ]. There is very little study on the effect of use of energy star marked refrigerators on actual reduction of energy consumption, especially in developing countries. Another important factor which contributes to the increase in consumption of electrical energy is door opening pattern in refrigerators. But there is very little study on the effect of door opening frequency in refrigerators on energy consumption especially in field condition. In the present work experimental study was conducted by keeping the door of a 5 star marked refrigerator open at different frequency but same total opening time. The result showed that frequent opening of door leads to substantial increase in energy consumption and increase in frequency is directly related to increase in energy consumption. The increase may be more than 100\% if a door is opened for even 1 minute after every 3 minutes or the door is kept open (by mistake or so) for a very long period (90minutes).
\end{abstract}

Keywords: energy, efficiency, refrigerator, star marking, compressor, door opening, frequency $* * *$

\section{INTRODUCTION}

The whole world has realized the catastrophic impact of severe energy crisis of the earlier days. As a result almost all the nations have taken measures to avoid such crisis. One such measure is to reduce consumption of electrical energy in the appliances. This measure not only results in saving energy but also saves the environment by saving fossil fuel and a huge amount of money, which otherwise would have to be spent for establishing new power producing facilities. As an important step of saving energy in appliances most of the countries have introduced a feature called standard and labeling of the appliances.

India had a total of 247 million households in 2011, with an average of about 4.9 people per household, according to Census of India. The World Bank estimated in their 2011 reports that if India's economy continues to grow as per projections, India's middle income group is likely to cross 583 million people by 2025. [Mckinsey Global Institute] Increase in the middle income group will definitely increase the purchase of household appliances by many times.

So, it is obvious that India will need a huge hike in energy to fulfill its requirements in the next decades. But, there is a large gap between the demand and supply. All India average energy shortfall is $9 \%$ and peak demand shortfall is $14 \%$ [O'Neill 2009]. Loss of electricity in India, due to transmission, is around 24\% during 2011-12. [Energy statistics 2013]
An affordable, reliable supply of energy is indispensible for sustainable economic development, but the staggering cost is a great burden in establishing new supply facilities. The simplest way out of this challenge is to use energy more efficiently. One of the most effective way of efficient use of energy is its proper use in household appliances.

\subsection{Energy Consumption in Residential}

\section{Refrigerators}

The refrigerators used for temporary storage of food in houses are called domestic refrigerators. Refrigerators are one of the largest energy consumers at home. Refrigerators have become more energy-efficient over time by making various processes that consume less energy and by preventing heat from entering the refrigerator.

The first record of energy efficient and eco-friendly refrigerator was the patented design by Albert Einstein with his colleague Leo Szillard in 1930s .

Various experiments have been already conducted by different persons using different techniques to improve the energy efficiency of refrigerators and airconditioners. Use of phase change material in condenser (Bansal et al,2003; Azzouz K, et al, 2009; C. Marques et al, 2013), use of variable frequency drive (VFD) and variable speed airconditioners (Annette Michele, 2009), microchip controlled 
defrost cycle and vacuum panel in wall (Zuckerman, 2007), innovative introduction of 'ecube' (Craig Berman, 2010) etc.. are examples of such techniques.

\subsection{Energy Use Behaviour}

Use of energy or rather energy-consuming appliances has direct bearing on the energy consumption. One such behaviour which leads to increase in energy consumption is the door opening pattern of residential refrigerators.

Seth Zuckerman,2007 has mentioned that opening of refrigerator door accounts for only $2 \%$ of appliance's energy use.

Gage 1995, Saidur et al 2002 and 2008, Hasanuzzaman et al 2008 have conducted certain experiments to ascertain the increase in consumption of energy with door opening time. Hossen and Hasan also experimented with the effect on performance of the refrigerator due to door opening, and remarked that there is substantial effect. They mentioned that a very few experimental and theoretical studies have been carried out on the analysis of effect of door opening on energy consumption.

A survey was conducted in Guwahati city in 2014 to find the number of houses having energy star marked refrigerator and the awareness of people about the energy star marking.

On the basis of literature review and survey conducted in Guwahati city, India an experimental study was conducted to find the increase in consumption of energy in a 5star marked refrigerator due to frequent opening of door.

\section{CASE STUDY}

A survey was conducted in three localities in Guwahati city by means of a questionnaire to more than three hundred households to have first hand information about the use of refrigerators by middle-income group people and their awareness of energy star marking.

The findings of results of this survey are as follows [Table 1 and Table 2]

Table 1 Number of households having refrigerators of different capacities

\begin{tabular}{|l|l|}
\hline $\begin{array}{l}\text { Capacity of } \\
\text { refrigerator in } \\
\text { ltr }\end{array}$ & $\begin{array}{l}\text { Number of } \\
\text { households }\end{array}$ \\
\hline$<185$ & 104 \\
\hline $185<210$ & 112 \\
\hline $210<250$ & 38 \\
\hline $250<280$ & 27 \\
\hline $280<350$ & 34 \\
\hline $350<550$ & 11 \\
\hline Total & 326 \\
\hline
\end{tabular}

Table 2 Number of households having refrigerators of different star marking

\begin{tabular}{|l|l|}
\hline $\begin{array}{l}\text { Star mark in } \\
\text { refrigerators }\end{array}$ & $\begin{array}{l}\text { Number of } \\
\text { households }\end{array}$ \\
\hline 0 & 53 \\
\hline 1 & 0 \\
\hline 2 & 0 \\
\hline 3 & 55 \\
\hline 4 & 112 \\
\hline 5 & 106 \\
\hline Total & 326 \\
\hline
\end{tabular}

The result of survey showed that even now many refrigerators are without any star marking in many households in Guwahati city. It is obvious that many more such refrigerators will be available in the rural area and other small towns in Assam. Further it is observed that only $32.5 \%(106 / 326)$ of the surveyed refrigerators are having 5 star marking, which is considered to be the most energy efficient. It shows the lack of awareness to the cause of energy saving among the people of this part of the country. As such, the practice of opening the door very frequently is quite common.

\section{FIELD TESTS OF DIFFERENT REFRIGERATORS}

Two sets of tests were conducted under the present work. First, the actual energy consumption by a non-star marked old refrigerator was tested and then the compressor of the same refrigerator was replaced by a compressor of a 5 -star marked refrigerator and tested to measure the energy consumptions. Thereafter one 4-star and another 5-star refrigerators were tested to measure the energy consumption. Results are shown in Fig.1.1 to Fig. 1. 6.

Another important factor is opening of the door of the refrigerator, which affects the energy consumption by the refrigerator. So, a set of tests were conducted to check this aspect.

A number of refrigerators with 5 Star marking have been tested under field (house / workshop) condition by keeping their doors open for different duration/frequency like 1 minute open after every 3 minutes closed condition, 5 minutes open after every 15 minutes closed, 10 minutes open after every 30 minutes closed, 15 minutes open after every 45 minutes closed and 1.5 hours continuous closed (if someone does not close the door properly and it remained open for $1.5 \mathrm{hrs}$ ) condition. The experiments are explained from 3.2.1 to 3.2.6.

\subsection{Experiments on Energy Consumption in}

\section{Domestic Refrigerators}

A series of experiments have been conducted under the present work to assess the energy consumption by a 165 liter domestic refrigerator without any star marking and subsequently compare the same with the other measured results. 
(i) at first measurements of power consumed by one no-star marked refrigerator (old model)

(ii) then energy consumption by the same refrigerator after replacing its compressor by a compressor from a 5-star marked refrigerator, because there may be various options available to save energy consumption in a domestic refrigerator. However, without going into design aspects of different components, the effect of the compressor may be observed.

(iii) the energy consumption by a 4-star marked refrigerator and to see the actual save in electrical energy due to use of energy-star marked refrigerator of same capacity.

(iv) the energy consumption by a 5-star marked refrigerator and to see the actual save in electrical energy due to use of energy-star marked refrigerator of same capacity.
The power consumption in the No-Star Refrigerator, the same refrigerator (No-Star) with a 5-star compressor, one 4star marked refrigerator and one 5-Star marked refrigerator of same capacity (165 litre) are measured and plotted in the graphs $1.1,1.2,1.4$ and 1.5 respectively. The comparative graph is shown in Fig. 1.3 and Line diagram in Fig. 1.6.

\subsubsection{Experiment No.1.1}

First of all, an old domestic 165 liter refrigerator, without any Star marking, has been taken as the baseline for testing. The Energy consumption of the refrigerator and temperature changing pattern in the freezer compartment were noted down for $6 \mathrm{hrs}$ continuously on three different days. This average energy consumption baseline is shown in Fig.1.1

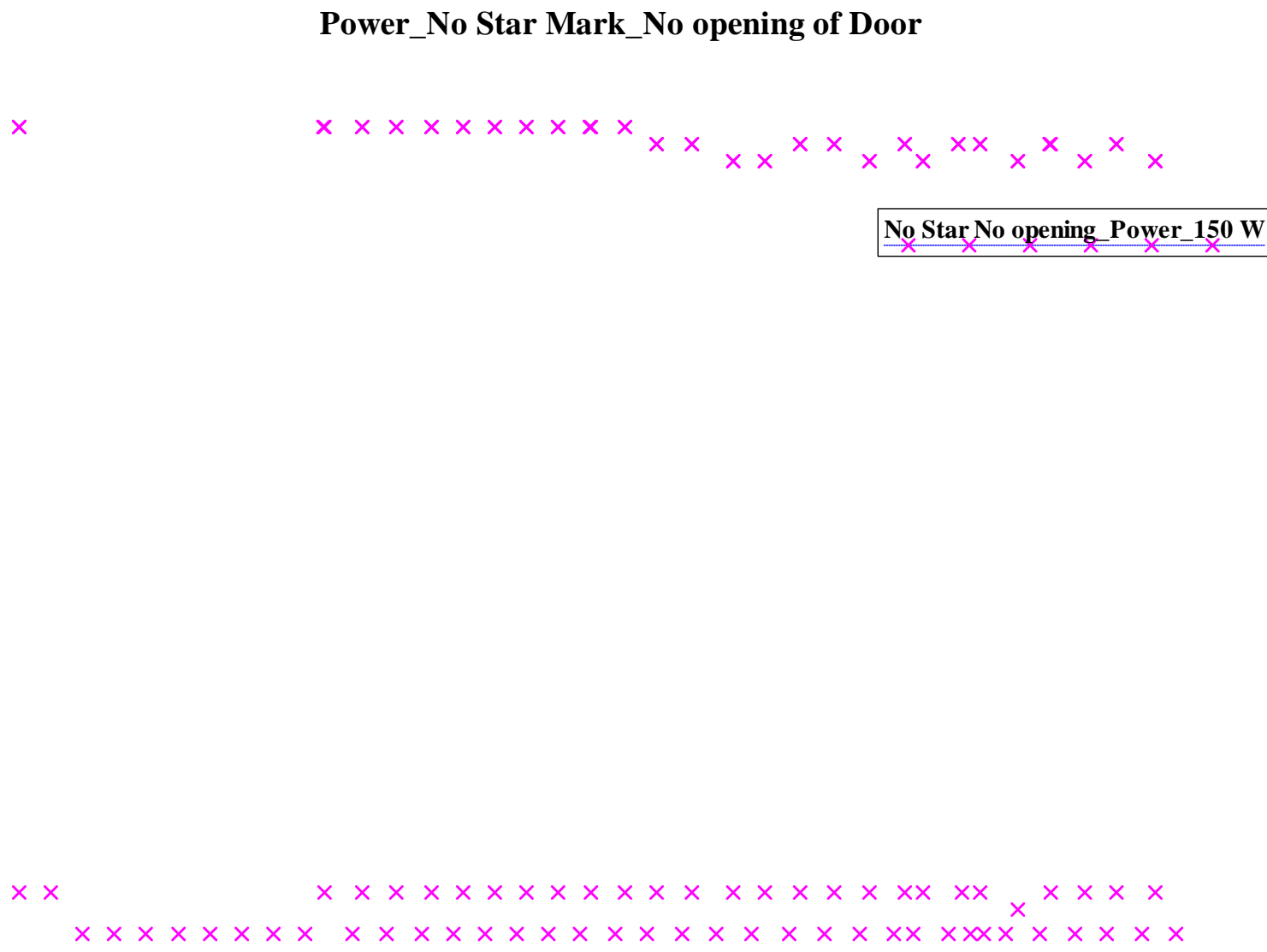

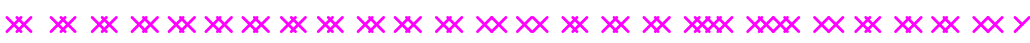

Fig 1.1 Power consumption in Watt vs Time in minutes in a domestic (165ltr) refrigerator having No-Star Marking

From the above graph (Fig 1.1), without opening the door of the refrigerator, it is found that power consumed by the refrigerator in 6 hours $=49462.6$ Watt minutes $=1204 \mathrm{kWHr}$ per annum (rounded to nearest whole number without considering the initial 90minutes separately)

\subsubsection{Experiment No.1.2}

Before exploring other factors the effect of the compressor in Energy Star Marked refrigerator is tested by changing the compressor of the same Non-Star marked Refrigerator by a compressor of a working 5-Star Marked Refrigerator and the result is shown below (Fig. 1.2): 


\section{No Star Refri with 5 Star Compressor}

○

$\begin{array}{lllllllllll}0 & 0 & 0 & 0 & 0 & 0 & 0\end{array}$

○ 0

$\circ \circ$

$0 \quad 0 \quad 0 \quad 0 \quad 0 \quad 0 \quad 0$

0000000000000000000000000000000000000

Fig 1.2 Power consumption by a No-Star Marked Refrigerator with a compressor of a 5-Star Marked Refrigerator (6 Hrs)

Total Power consumption in $6 \mathrm{hrs}=35510.15$ Watt Minute (without considering the effect of $1^{\text {st }} 75$ minutes required for initial cooling) i.e $864 \mathrm{kWHr}$ per Annum

The two graphs shown in Fig. 1.1 and 1.2 are superimposed in a third graph and the power consumption in refrigerator with nostar and another with 5-star compressor placed in a no-star refrigerator (comparative) is shown in Fig. 1.3 


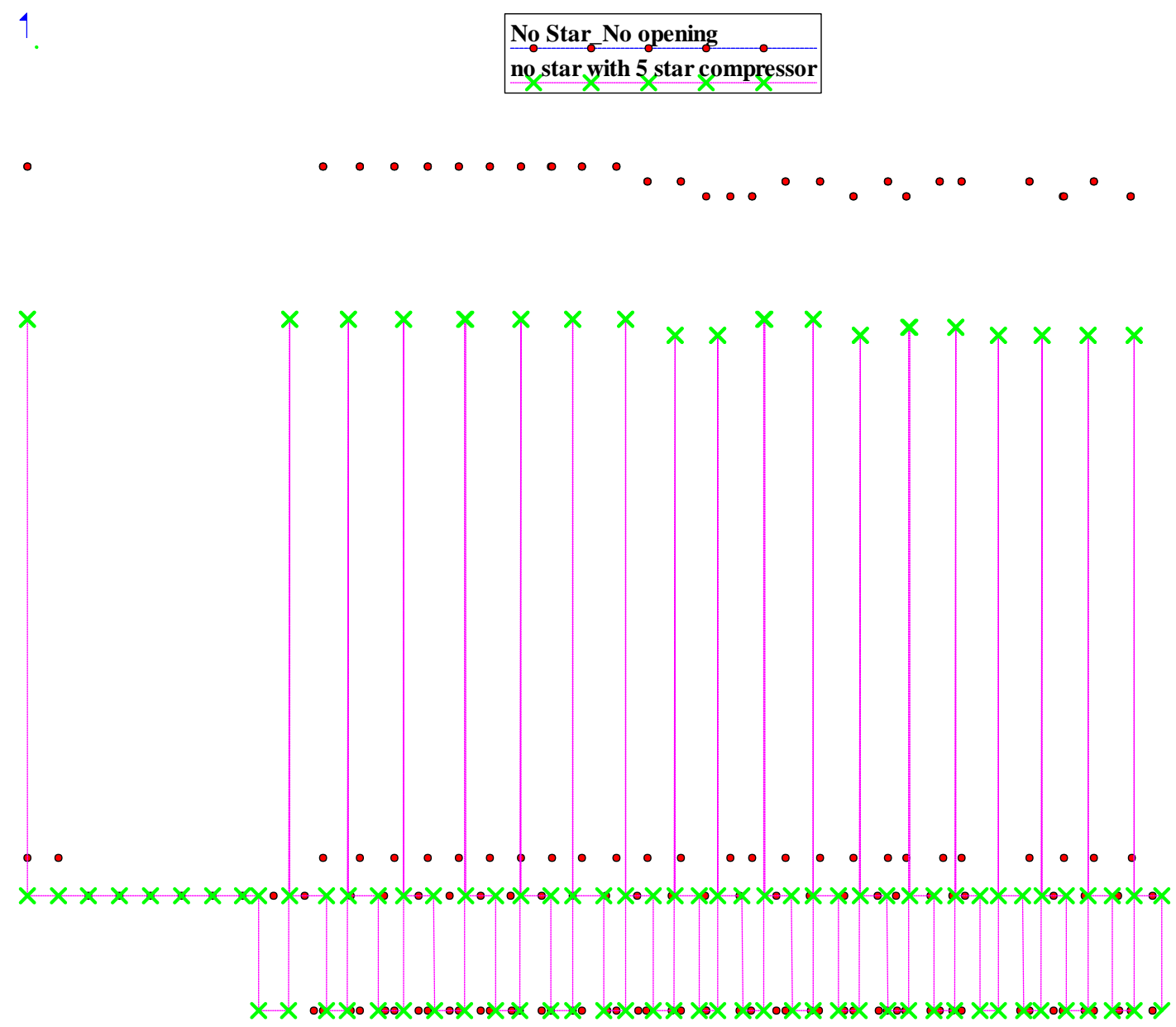

Fig. 1.3: Time vs. Power consumption in (i) a No-Star marked refrigerator and (ii) a No star marked refrigerator with compressor of a 5 star marked refrigerator.

If detailed analysis is done then the saving is as follows:

(i) Refer to Fig. 1.3 In the No-Star Refrigerator,

Power: $14281.5+35181.1=49462.6$ watt.minute (in 6hrs)

Excluding $1^{\text {st }} \mathrm{hr}, 35181.1$ watt.minute in $4.5 \mathrm{hrs}$, so in $24 \mathrm{hrs}$

Power consumption $=(35181.1 / 4.5) \times 24 \quad=187632.53$ watt.minute,

If we consider the additional $(14281.5-11727 *)=2554.5$ watt.minute (the excess amount required in the initial cooling) [* 35181.1 watt $\min$. in $4.5 \mathrm{hrs}$, so $35181.1 / 3=11727$ watt min. in $1.5 \mathrm{hrs}$ ]

Then annual power consumption:

i.e. In 365 days $=\{2554.5+(187632.53 \times 365)\} / 60=1141473.79$ watt.hr $=\mathbf{1 1 4 1} \mathbf{~ k W h r}$ (rounded to nearest integer)

(ii) Similarly, in the same refrigerator with compressor of a 5 star fridge,

Consumption in initial 60 minutes $=9026.25$ watt.minutes

Power : $9026.25+26483.9=35510.15$ watt.minute in $6 \mathrm{hrs}$

Excluding $1^{\text {st }} \mathrm{hr}, 26483.9$ watt.minute in $5 \mathrm{hrs}$,

So in 24 hrs, power consumption $=(26483.9$

15)X24

$=127122.72$ Watt.minute

If we consider the additional (9026.25-26483.9/5) = 3729.47 watt.minute,

Then, annual power consumption i.e. In 365 days

$=(3729.47+127122.72 \times 365) / 60=773392$ watt.hr $=\mathbf{7 7 3} \mathbf{~ k W h r}$ (rounded to nearest integer)

It shows that by changing only the compressor of the No-Star Marked refrigerator by that of a 5-Star Marked refrigerator, we can save electrical energy by an amount of $1141-773=368 \mathrm{kWHr}$, i.e $(368 / 1141) \mathrm{X} 100 \%=\mathbf{3 2 . 2} \%$ saving or if it is considered the other way i.e. replacing a no-star refrigerator with 5-star compressor by a simple no-star refrigerator then the additional energy requirement in percentage $=368 / 773 \times 100 \%=47.6 \%$ increase. 


\subsubsection{Experiment No.1.3}

The next experiment is done with a HAIER 4-star refrigerator. Refrigerant R-134a and capacity 165litre. Power consumption of this refrigerator over 6 hours is shown in Fig. 1.4

Fig. 1.4 Time vs power in watt of a 4-star marked refrigerator

From the graph, the consumption of power is calculated as follows

For initial 60 minutes power consumption $=5440.9$ watt. minutes

The consumption during 60 minutes to 360 minutes $=15978.15$ watt minutes

Since the initial 60 minutes cooling time is required only once, it is calculated separately.

On the basis of power consumption during next 5 hours, the total consumption in one year $=(15978.15 / 5) \times 24 \times 365=$ 27993718.8 watt .minutes

So, considering the additional power required for initial cooling $=(5440.9-15978.15 / 5)=2245.27$ watt. minutes

Thus the actual power consumption of 4 star refrigerator per year $=2245.27+27993718=27995964$ watt. $m i n u t e s=\mathbf{4 6 7} \mathbf{k W H r}$

\subsubsection{Experiment No. 1.4}

Power consumption of a 5 star fridge (HAIER) of capacity 165 liter. 
Haier 5 Star Refrigerator

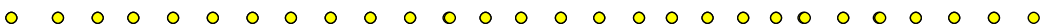

00000000000000000000000000000000000000000000000000000000000000

00000000000000000000000000000000000000000000000000000000

Fig. 1.5 Time in minutes vs Power in watt of a 5-star refrigerator

In the experiment No.4 Fig.5.2.5, where the energy consumption by a 5 star refrigerator

For initial 60 minutes $=4825.2$ watt.minutes

For next 300 minutes $=14762.28$ watt.minutes

On the basis of power consumption during next 5 hours, the consumption per year

$=(14762.28 / 5) \mathrm{X} 24 \mathrm{X} 365=25863514$ watt.minutes

The additional power required in the initial hour $=(4825.2-14762.28 / 5)=1872.75$ watt.minutes

Actual consumption $=1872.75+25863514=25865386.75$ watt minutes $=431 \mathrm{kWHr}$.

The increase in power consumption when a 4 -star refrigerator is used in place of a 5 star refrigerator $=(467-431) / 431=0.083=8.3$ $\%$

The energy consumption by these refrigerators are shown in a line diagram in Fig1.6 


\section{Power consumption in KWHr per annum}

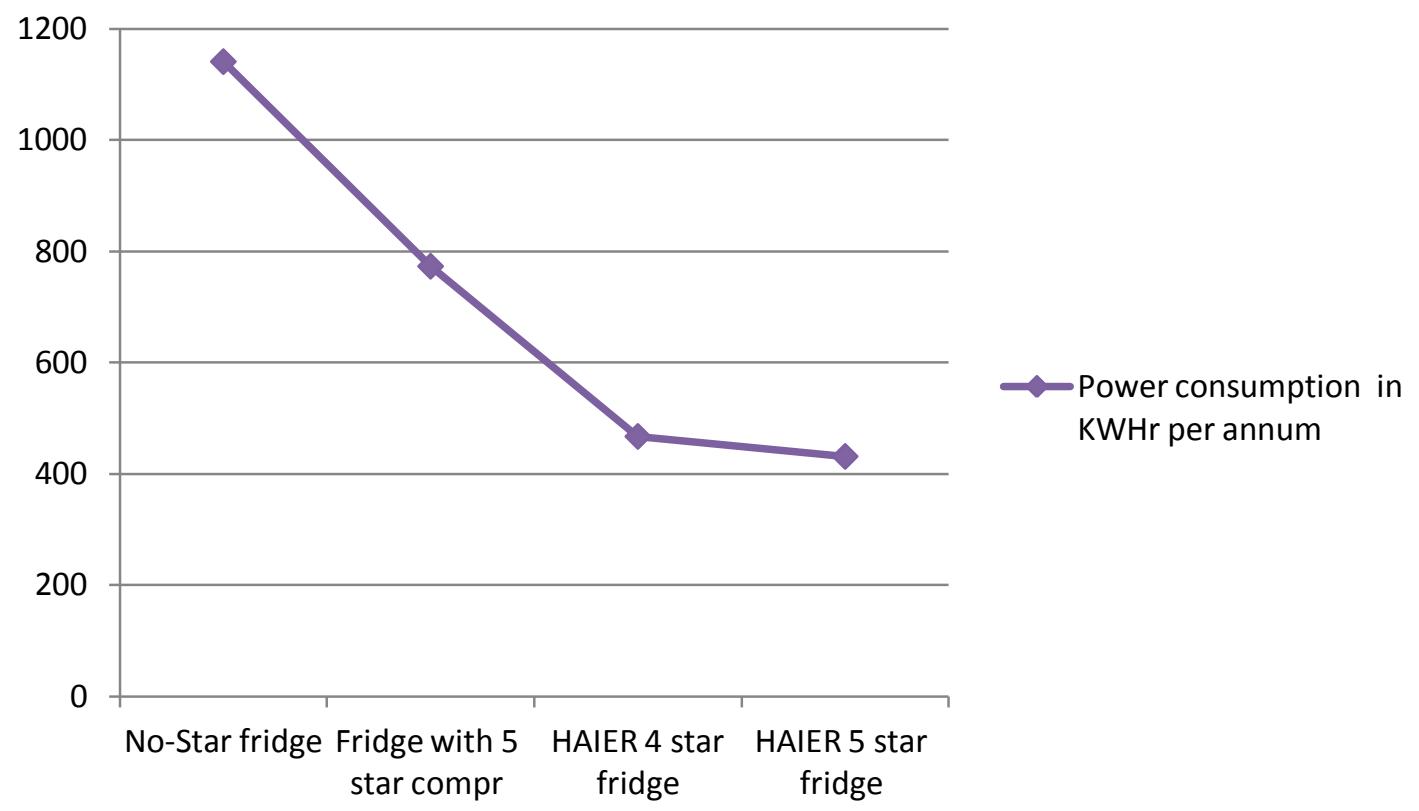

Fig. 1.6 Line chart showing decrease in power

\subsection{Experiments with Different Door Opening Frequency}

In order to test the impact of keeping the door open for $1 / 4^{\text {th }}$ of total time, the door of the refrigerator was kept open for the same total time i.e. 90 minutes in total 360 minutes. However the duration of door opening is changed so that the frequency of opening is also changed to keep the total opening time same. It is done as follows

(i) 1 minute in every 4 minutes i.e. 1 minute open and then 3 minutes closed,

(ii) 5 minutes open every 15 minutes or 5 minutes open and then 15 minutes closed ,

(iii) 10 minutes open in every 30 minutes i.e. 10 minutes open and then 30 minutes closed,

(iv) 15 minutes after every 45 minutes i.e. 15 minutes open and then 45 minutes closed and

(v) 1.5 hours (90 minutes) continuous open. All these experiments were conducted for continuous six hours under no-load condition as per BEE norms and in all these experiments total time of keeping the door open was 90 minutes in total 360 minutes (6 hrs).

\subsubsection{Experiment No.2.1}

Experiment to calculate power consumption by a 5 Star Refrigerator without opening the door for 6 hours: Model : HAIER Capacity: 165 litre 
Haier 5 Star Refrigerator

O

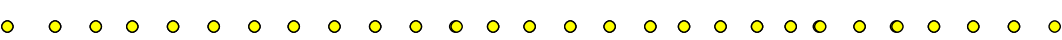

00000000000000000000000000000000000000000000000000000000000000

00000000000000000000000000000000000000000000000000000000

Fig2.1 Power consumption of a 5-Star Energy Marked Refrigerator without opening the door for 6 hours.

Total power consumption (from graph) watt. minute $=431 \mathrm{kWHr}$ (kiloWatt Hour)per annum

It is considered as reference or baseline value for comparison with the power consumed at different door opening frequency and duration.

\subsubsection{Experiment No. 2.2}

Same refrigerator is tested by keeping the door open for 15 minutes after every 45 minutes i.e total 15 minutes in one hour or $15 \times 6=90$ minutes in 6hours. 


\section{5 mins open after every 45 mins}

$\circ$
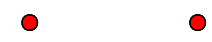

$\circ \circ$
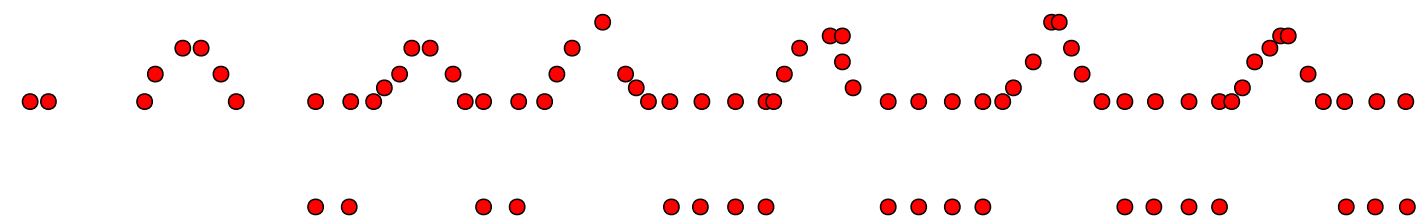

$\circ \circ \circ \circ$

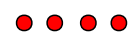

$\circ \circ \circ \circ$

Fig 2.2: Power consumption of Refrigerator with door open for 15 minutes

From the above graph [Fig.2.2], energy consumption during initial $60 \mathrm{mins}=5455.2$ watt.mins Next 300 mins = 22234.3 watt. Mins

Annual consumption on the basis of later 5 hours $=(22234.3 / 5)$ X 24 X365=38954493.6 watt.mins

Now adding the additional power in initial $60 \mathrm{mins}=(5455.2-22234.3 / 5)+38954493.6=38955501.6$ watt. $\mathrm{mins}=649$ $\mathrm{kWHr}$ (rounded to nearest integer)

Increase in percentage of Energy Consumption $=(649-431) / 431 * 100 \%=50.58 \%$

\subsubsection{Experiment No. 2.3}

Same Refrigerator is tested by keeping the door open for 10 minutes after every 30 minutes i.e 10 minutes in every 40 minutes or 90 minutes in total 6 hours. 


$\times \quad \times \quad \times \quad \times \quad \times \quad \times \quad \times \quad \times \quad \times$

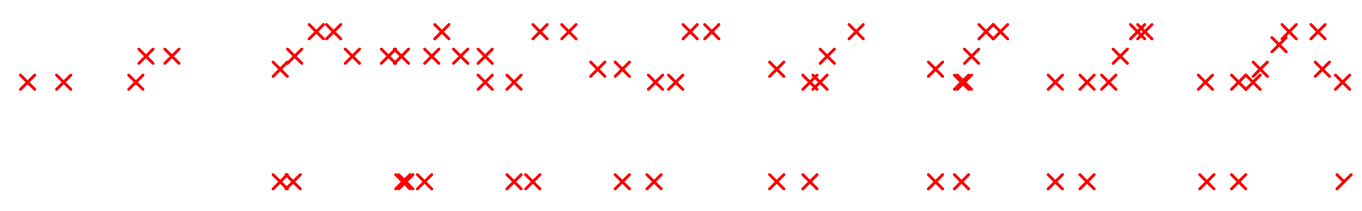

Fig. 2.3 Power consumption of Refrigerator with door open for 10 minutes in every 40 minutes

When the door is kept open for $\mathbf{1 0}$ minutes after every 30 minutes:

Power during initial 60 minutes $=5328.3$ watt.minutes

Power during next 5 hours $\quad=26406.4$ watt.minutes

Power consumption in 365days $=(26406.4 / 5)$ X 24 X $365=46264012.8$ Watt minute

Total power consumption including initial additional power $=(5328.3-26406.4 / 5)+46264012.8=46264059.82$ watt minutes $=$ $771 \mathrm{kWHr} / \mathrm{yr}$

Increase in percentage of Energy consumption $=(771-431) / 431 * 100 \%=78.8 \%$

\subsubsection{Experiment No. 2.4}

Same Refrigerator is tested by keeping the door open for 5 minutes after every 15 minutes or 90 minutes in total 6 hours. 


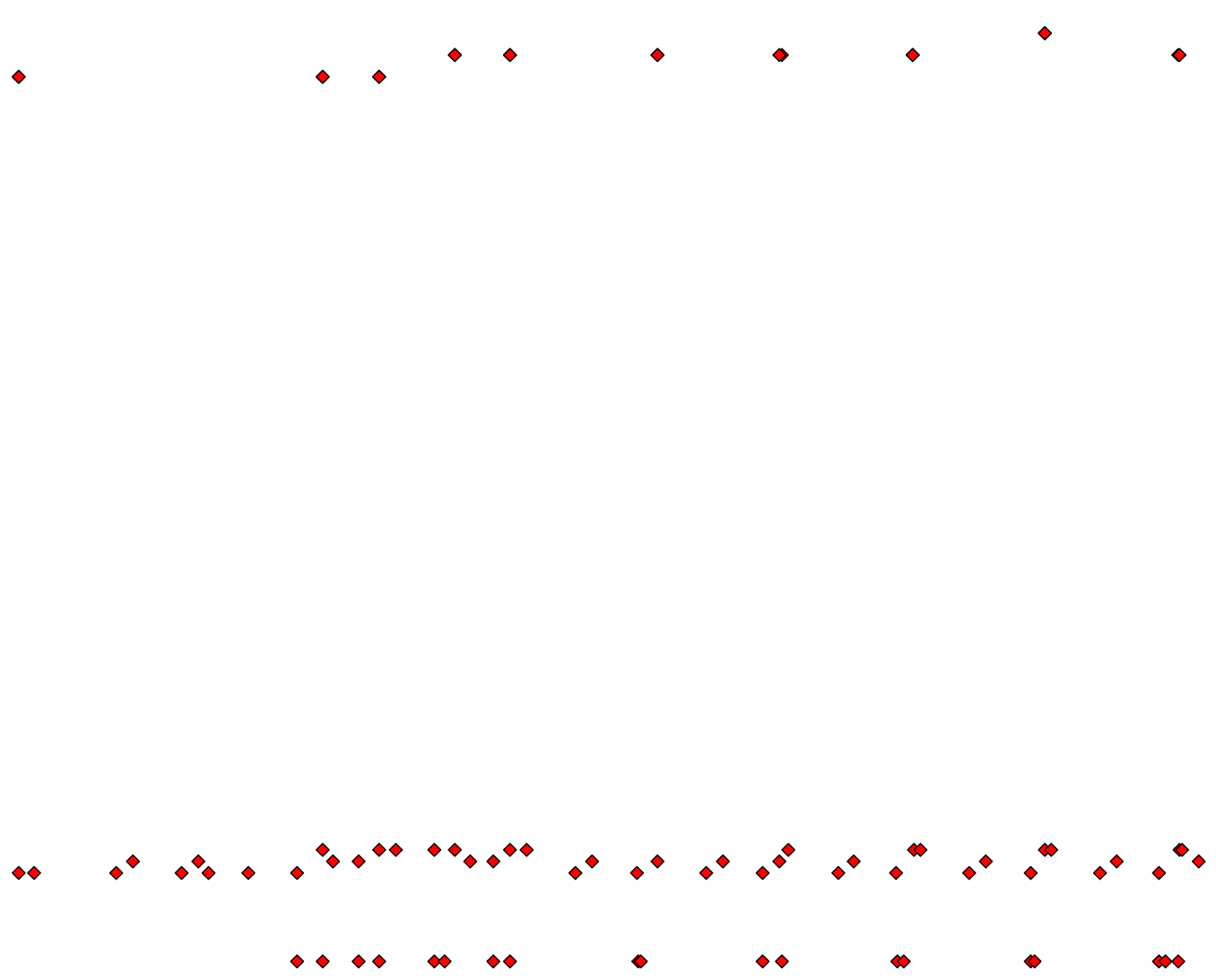

Fig 2.4: Power consumption of Refrigerator with door open for 5 minutes

Power consumed during initial 60 minutes $=4965.2$ watt.mins

Power consumption during next $300 \mathrm{mins}=27319.7$ watt.mins

On the basis of next 300 mins, energy consumption per annum $=(27319.7 / 5) X 24 X 365=47864114.4$ watt.mins

Considering additional power consumed during initial $60 \mathrm{mins}$, total power consumption $=(4965.2-27319.7 / 5)+47864114.4=$ 47863615.7 watt. $\mathrm{mis}=798 \mathrm{kWHr}$

Total Consumption When door is kept open for 5 minutes after every 15 minutes $=36112.4$ Wwatt minute $=798 \mathrm{kWHr}$ per annum

Increase in percentage of Energy Consumption $=(798-431 \quad) / 431 * 100 \%=85.1 \%$

\subsubsection{Experiment No 2.5}

Same refrigerator is tested by keeping the door open for 1.5 hours continuously 


\section{5 hrs continuous open after 135 mins}

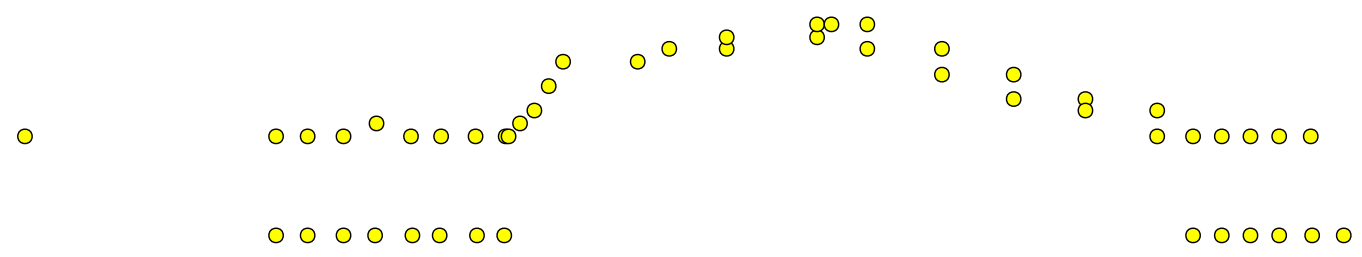

Fig 2.5 Power consumption of Refrigerator with door open for 90 minutes continuously 135 minutes of starting

Initial 60 mins $=4825.2$ watt.mins

Next five hours $=30419.55$ watt.mins

On the basis of next five hours, consumption $=(30419.55 / 5)$ X 24 X365 =53295051.6 watt.mins

Considering initial 60 mins , consumption $=(4825.2-30419.55 / 5)+53295051.6=53293792.89$ watt.mins $=888 \mathrm{kWHr} / \mathrm{annum}$ Increase in percentage of Energy Consumption $=(888-431) / 431 * 100 \%=106 \%$

\subsubsection{Experiment No. 2.6}

Same Refrigerator is tested by keeping the door open for 1 minute after every 3 minutes.: 


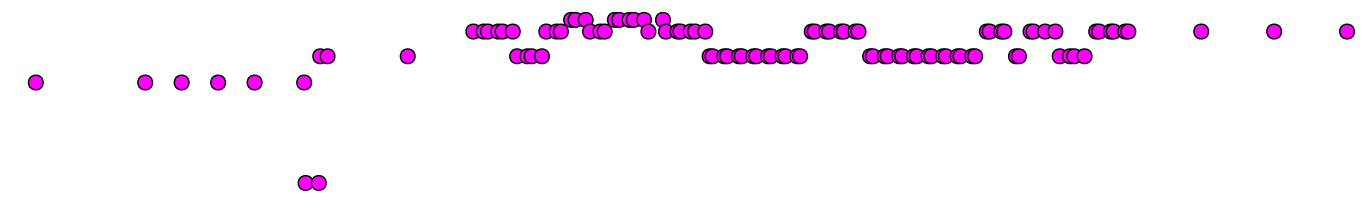

Fig 2.6: Power consumption in Watt vs. Time (when door is kept open for 1 min after every 3 mins)

Since the opening started from very beginning, so there is no need to consider initial cooling time.

Hence, total power consumption in 6 hours $=37772.4$ Watt minute (as calculated from the above graph) $=919 \mathrm{kWHr}$.

Percentage increase in power consumption $=(919-431) / 431 * 100 \%=113 \%$

\section{CONCLUSION}

Though there are many skeptical views regarding effectiveness of the Energy Star Marking on appliances, but the extensive tests conducted during this research work clearly showed marked improvement in reduction of energy consumption by the appliances having energy star markings.

However, it is also true that actual energy consumption by the appliances are much above the rated consumption, because the rated consumption are on the basis of tests conducted under laboratory condition while the tests conducted during this research work are under actual field condition.

From the graphs shown in Fig. 1.1 to 1.6, the power consumption of the refrigerators are as follows:

Table 3 : Comparison of different Refrigerators' power consumption

\begin{tabular}{|l|l|}
\hline Star rating of Refrigerator & Power consumption in KWHr per annum \\
\hline No-Star Refrigerator & 1141 \\
\hline No-star Refri with 5 Star compressor & 773 \\
\hline HAIER 4 star refrigerator & 467 \\
\hline HAIER 5Star Refrigerator & 431 \\
\hline
\end{tabular}




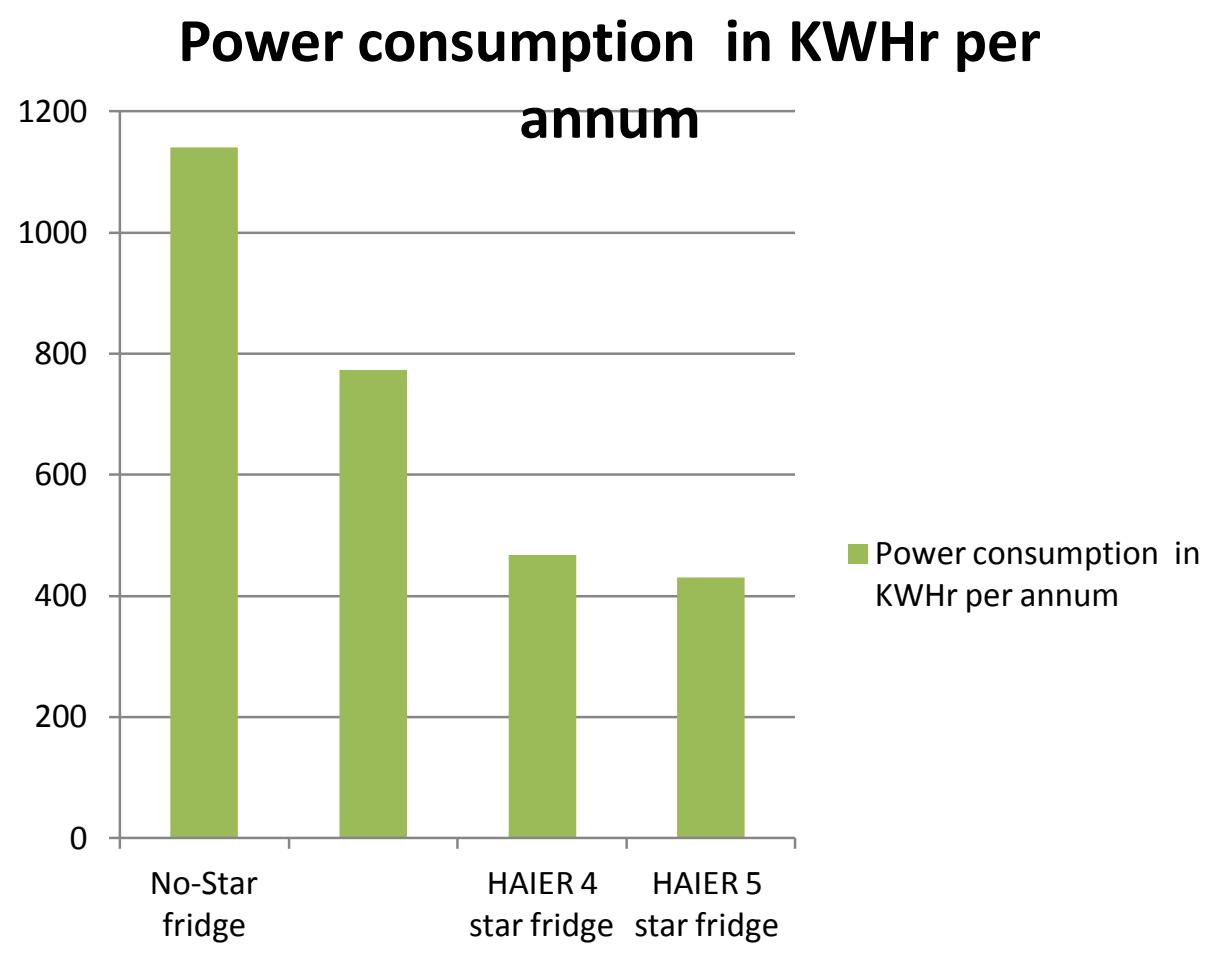

Fig. 3.1 Bar diagram showing the energy consumption (kWHr) in refrigerators

It is observed that there are substantial effects on energy consumption of a domestic refrigerator when the door is opened for different interval of time. When it is compared with the baseline energy consumption of a 5-star marked refrigerator without opening the door, the observed increase in consumption of energy are as follows

In case of baseline consumption $=431 \mathrm{kWHrper}$ annum $(5$ Star Refrigerator without opening the door is tested as shown in Experiment No.2.1 Fig.2.1)

Power consumption at different frequency of door opening are as follows

(a) 15 minutes open after every 45 minutes per $6 \mathrm{hrs}$, the consumption is 23042.9 Watt minute $=649 \mathrm{kWHr}$ (rounded to nearest integer)

Increase in percentage of Energy Consumption $=(649-431) / 431 * 100 \%=50.58 \%$

(b) In case of keeping the door open for 10 minutes after every 30 minutes, power consumption in 6 hours $=32003.2$ Watt minute (as calculated from the above graph)

$=771 \mathrm{kWHr} / \mathrm{yr}$.

Increase in percentage of Energy consumption $=(771-431) / 431 * 100 \%=78.8 \%$

(c) In case of 5 minutes after every 15 minutes $=36112.4$ Watt minute $=798 \mathrm{kWHr}$ per annum

$$
\text { Increase in percentage of Energy Consumption }=(798-431 \quad) / 431 * 100 \%=85.1 \%
$$

(d) In case of 1.5 hour open continuously after every 120 minutes from start, for $6 \mathrm{hrs}$, the consumption is $37727 \mathrm{Watt}$ minute $=$ $888 \mathrm{kWHr} / \mathrm{annum}$

$$
\text { Increase in percentage of Energy Consumption }=(888-431) / 431 * 100 \%=106 \%
$$

(e) In case of 1 min open after every 3 minutes, the consumption is $919 \mathrm{kWHr}$.

Percentage increase in power consumption $=(919-431) / 431 * 100 \%=113 \%$ 
The results are shown in Table 2 and Fig 3.2 and Fig. 3.3 below

Table 2 Effect of Door opening time of refrigerator on Energy consumption

\begin{tabular}{|l|l|l|l|}
\hline Door open time & $\begin{array}{l}\text { Energy consumption } \\
\text { per Annum (KWHour) }\end{array}$ & $\begin{array}{l}\text { Percentage increase over } \\
\text { baseline } \\
\text { Refrigerator 5star } \\
\text { opening the door) }\end{array}$ & $\begin{array}{l}\text { Remark } \\
\text { opening thout } \\
\text { hours) }\end{array}$ \\
\hline Without opening door & 431 & ---- & Baseline \\
\hline $\begin{array}{l}15 \text { minutes open after } \\
\text { every 45 minutes }\end{array}$ & 649 & $\mathbf{5 0 . 5 8 \%}$ & Total 90 min \\
\hline 10 min after 30 min & 771 & $\mathbf{7 8 . 8 \%}$ & Total 90 min \\
\hline 5 min after 15 min & 798 & $\mathbf{8 5 . 1 \%}$ & Total 90 min \\
\hline $\begin{array}{l}1.5 \text { hour open } \\
\text { continuously }\end{array}$ & 888 & $\mathbf{1 0 6 \%}$ & Total 90 min \\
\hline 1 min after 3 min & 919 & $\mathbf{1 1 3 \%}$ & Total 90 min \\
\hline
\end{tabular}

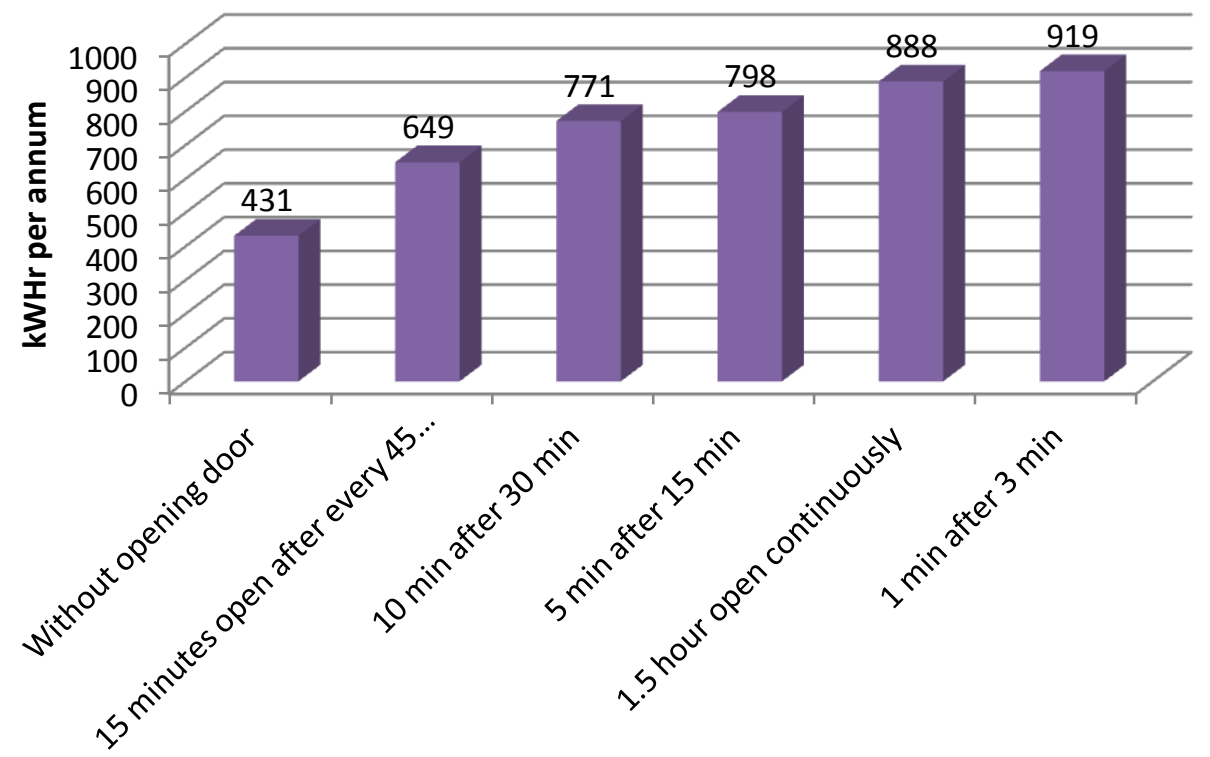

Fig. 3.2 Energy consumption per annum vs door opening time

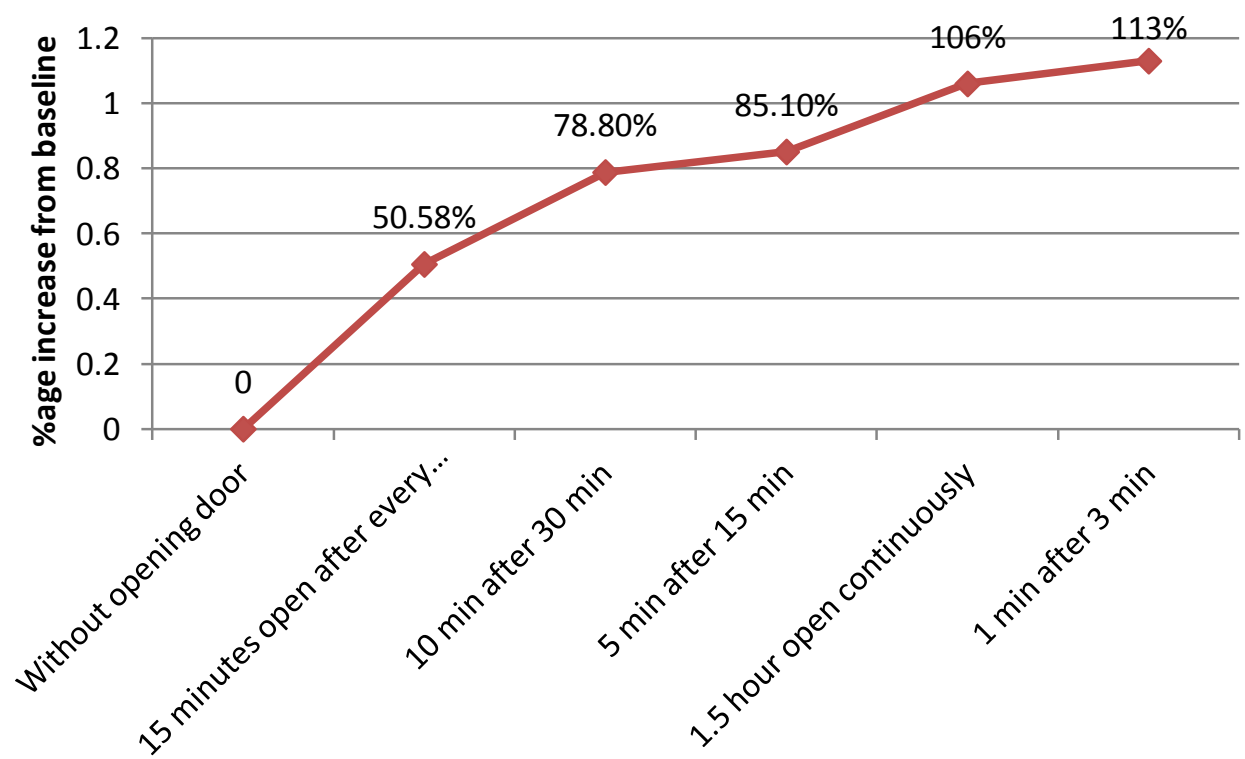

Fig. 3.3: Percentage increase in energy consumption compared to consumption when the refrigerator runs without opening the door. 
From the Table 2, it is observed that keeping the door open for a longer duration (total 90 minutes per 6 hours) substantially increases the consumption of electrical energy. In the above experiments, the refrigerator used was HAIER 5 star marked refrigerator with R-134a as refrigerant. Thermostat setting was 'freezer maximum'. Ambient temperature is $32^{\circ} \mathrm{C}$.

It is observed that the consumption of energy increases when the frequency of opening increases. The increase is maximum when the door is opened for only 1 minute after every 3 minutes for total 6 hours, so that total opening time in 6 hours remains 90 minutes. It is mainly because the door gets opened before the thermostat reaches its minimum temperature at which the compressor gets 'OFF'.

It is evident from the graph that the compressor remained in running position i.e. kept on running without any break (OFF) after about 90 minutes from starting. Before that the effect of 1 minute opening was not evident. So, it is clear that opening the door for only 1 or 2 minutes will not have much effect on energy consumption if it is not repeated at frequent interval. In other words, it is important to keep the door closed for sufficient time so that the temperature drops and reaches the set temperature of the thermostat within reasonable time and the compressor stops. If the door is opened before the temperature drops to thermostat set value, then the temperature will increase again, thereby increasing the running time of the compressor, which will lead to more consumption of electrical energy.

In Assam, the off-peak load demand is $850 \mathrm{MW}$ and peak load demand is 1200 MW. (The peak load demand of Guwahati city is 330 MW peak load and $250 \mathrm{MW}$ off peak load as on $19^{\text {th }}$ February,2015).

The corresponding shortfalls in Assam are 87 MW and 236 MW respectively as on $19^{\text {th }}$ February'2015 [source: NER Load Dispatch Centre \& State Load Dispatch Centre].

As Assam is not highly industrialized area, if residential load is taken as $50 \%$ of the total load, then the load for residential use will be 425 MW (off-peak load) and 600 MW (peak load) respectively.

According to BEE [Energy and Buildings, 2014] $13 \%$ of residential electricity is used by refrigeration systems. So, the daily energy consumption by refrigeration system in Assam at this rate will be $13 \%$ of $425=55.25$ MW (offpeak load) and $78 \mathrm{MW}$ (peak load).

If increase in frequency of door opening leads to increase in energy consumption by 50 to $113 \%$, then by maintaining the door opening frequency to minimum, this amount of electricity could be saved.

Considering $30 \%$ of people using frequent door opening, the wastage of electricity will be $30 \%$ of $55.25=16.575 \mathrm{MW}$ and $30 \%$ of $78=23.4 \mathrm{MW}$ respectively. Even at $50 \%$ increase in energy rate will be equivalent to $11 \mathrm{MW}$ and
15.6 MW respectively. In a state like Assam, where there is daily shortfall of electricity of 87MW and $236 \mathrm{MW}$, this could be a substantial saving.

\section{REFERENCES}

[1]. O’Neill J. Global Economics Paper No: 192 The LongTerm Outlook Dec4, 2009

[2]. Energy Statistics,2013, Central Statistics Office , Ministry Of Statistics And Programme Implementation, Government of India, New Delhi (www.mospi.gov.in)

[3]. Vijay M Deshpande Labeling Design Effort in India: Lessons Learned, Nexant Inc. New Delhi, page1

[4]. CSE india Energy and Building,2014 Graph: End use of electricity in commercial and residential buildings page 3,5 (source BEE \& Mckinsey Global Institute)

[5]. Azzouz K, D. Leducq , D.Gobin Enhancing the performance of household refrigerators with latent heat storage: An experimental investigation International Journal of Refrigeration 11/2009; 32(7):1634-1644.

[6]. Anette Michel, Eric Bush, Jürg Nipkow, Conrad U. Brunner, Hu Bo Energy efficient room air conditioners best available technology (BAT) page 74 and page 25

[7]. Zuckerman Seth: The New Wave Of Energy Efficient Refrigerators,(2007) page3

(http://www.ecomall.com/greenshopping/icebox2.htm)

[8]. Creig Breman : Enhancing energy efficiency in Refrigeration published in Drives \& Switchgear Nov/Dec 2010

[9]. Hasanuzzaman M, Saidur R and Masjuki H.H. in the research article : Investigation of Energy Consumption and Energy Saving of Refrigerator-Freezer During Open and Closed Door Condition, published in Journal of Applied Sciences, 8: 1822-1831.(2008)

[10]. Khan Md. Imran Hossen and Hasan M.M. Afroz: An Experimental Investigation of Door Opening Effect on Household Refrigerator; the Perspective in Bangladesh (2014) 